\title{
Advantages of Computed Tomography (CT) in Endoscopic Septopasty
}

\author{
Md. Ashraful Islam ${ }^{1}$ (), Towsif Bin Mamoon ${ }^{2}$, Farid Uddin Milki², Nazmul Hossain Chowdhury33, \\ Saif Rahman Khan", A. S. M. Rahman5', Tareq Mohammad ${ }^{3}$
}

${ }^{1}$ MBBS, FCPS, FICS, FRCS (Glasgow), Otolaryngology-Head \& Neck Surgery, Bangladesh Medical College Hospital, Dhaka, Bangladesh

${ }^{2}$ MBBS, ENT, Bangladesh Medical College Hospital, Dhaka, Bangladesh

${ }^{3}$ MBBS, FCPS, ENT, Bangladesh Medical College Hospital, Dhaka, Bangladesh

${ }^{4}$ MBBS, ENT, National Institute of ENT, Dhaka, Bangladesh

${ }^{5}$ MBBS, MCPS, DLO, MRCPS (Glasgow), Bangladesh Medical College Hospital, Dhaka, Bangladesh

Email: ashrafis123@yahoo.com, towsif708@gmail.com, fariduddinmilki@gmail.com,caesar23rd@gmail.com, khan_saif@rocketmail.com,drlutfurent@gmail.com,tareqmohammad2013@gmail.com

How to cite this paper: Islam, Md.A., Mamoon, T.B., Milki, F.U., Chowdhury, N.H., Khan, S.R., Rahman, A.S.M. and Mohammad, T. (2020) Advantages of Computed Tomography (CT) in Endoscopic Septopasty. International Journal of Otolaryngology and Head \& Neck Surgery, 9, 185-193. https://doi.org/10.4236/ijohns.2020.96022

Received: August 7, 2020

Accepted: September 27, 2020

Published: September 30, 2020

Copyright $\odot 2020$ by author(s) and Scientific Research Publishing Inc. This work is licensed under the Creative Commons Attribution International License (CC BY 4.0).

http://creativecommons.org/licenses/by/4.0/

\begin{abstract}
Background and objective: Nasal obstruction is the most frequent presentation to the otolaryngologist all over the world. Symptoms are multisystem involvement such as headache, epistaxis, ophthalmological, otological, upper and lower respiratory tract infections; and many more. Septoplasty is commonly performed for nasal septal deviation as a primary indication of nasal airway obstruction. Physical examination, anterior rhinoscopy and nasal endoscopy are considered the gold standard for detecting septal deviation. Computed tomography (CT) can also be used to evaluate the nasal septum, anatomical variants and unveils the associated sinonasal diseases. This study aimed to find out the advantages of CT in endoscopic septoplasty for all out benefits to the patients. Patients and methods: 168 patients of nasal septal deviation were selected from 2015 to 2018 in the Bangladesh Medical and Popular Medical College Specialized Hospital. Age ranged between 10 years to 70 years of age. CT scanning in both coronal, axial and sagittal sections had been done in all patients after proper history taking, physical examination, anterior rhinoscopy and nasal endoscopy. Endoscopic septoplasty alone and/or other ancillary procedures were performed in all 168 patients under general anesthesia. Results: Amongst 168 patients, male was $116(69 \%)$ and female was $52(31 \%)$ with a ratio 2.2:1. Maximum 58 (35\%) reported in 31 to 40 years and $48(29 \%)$ was found in 21 to 31 years of age. Hypertrophied inferior turbinate (HIT) 54 (32\%) and 48 (29\%) concha bullosa (CB) were associated with 168 septal deviation. Associated pathologies like maxillary antral cyst $68(40 \%)$ and maxillary sinusitis $62(37 \%)$
\end{abstract}


were documented. Conclusion: CT scanning unveils the abnormal anatomic variants and associated sinonasal pathologies along with nasal septal deviation. Endoscopic septoplasty, correction of the anatomical variants and complete surgical clearance of the sinonasal pathologies can give the patient a grand success.

\section{Keywords}

Computed Tomography, Endoscopic Septoplasty, Advantage

\section{Introduction}

Nasal obstruction is one of the most common symptoms of the patients encountered in otolaryngological practice. Septal deviation is the major cause of nasal obstruction. Coronal CT shows nasal septal deviation by distance measured from the midline (severity) and height from the nasal floor [1]. There are many other pathologies in the nose and paranasal sinuses responsible for nasal obstruction such as hypertrophied inferior turbinate (HIT), concha bullosa (CB), chronic rhinosinusitis (CRS), nasal polyps, mucocele, mucous retention cyst in the paranasal sinus, tumors, adenoid hypertrophy and many more may be associated with septal deviation. This nasal obstruction leads to snoring, obstructive sleep apnea (OSA), otological symptoms, headache, facial pain, etc. Physical examination, anterior rhinoscopy (AR) and nasal endoscopy (NE) are considered the "gold standard" to evaluate septal deviation [2]. These examination tools have limitations to find the high and posterior deviations as well as the septal pneumatization. Septal deviation is usually associated with compensatory HIT and $\mathrm{CB}$ /paradoxical middle turbinate (PMT). It is not only caused by mucosal hypertrophy, but also by hypertrophy of the inferior and middle turbinate bone [3]. The assistance of preoperative CT scanning can detect those anatomical septal and turbinate variants in details; and is invaluable in the detection of nose and paranasal sinus diseases for its subsequent and effective management [4]. The costs and radiation hazards of CT are used to be considered as an initial additional burden in septal surgery but correction of other variants and pathologies at the same sitting give rise to long term benefits to the patient that prevent second surgery indeed [5]. With the introduction of cone beam computed tomography (CBCT) in the Head-neck region and in oral-maxillofacial/dentistry, the costs and harmful effects of radiation have reduced to a great extent [6]. The advent of nasal endoscope has revolutionized the diagnosis and treatment modalities of nose and paranasal sinus diseases and has widened the horizon of rhinology [7] [8]. Lanza et al. and H. Stammberger initially described the application of endoscopic technique for the correction of septal deformity in 1991 [9]. Nasal endoscope has the advantage to deal in complex deformities particularly high and posterior septal deviation resulting better septal correction and thus is gaining its popularity. Endoscope also aids in limited septal resection and re- 
moves ancillary sinonasal abnormalities thus more patient benefit is achieved [10] [11].

The aim of this study is to evaluate the advantage of preoperative computed tomography (CT) scanning in endoscopic septoplasty.

\section{Materials and Methods}

168 patients of nasal septal deviation were included in the study in the Bangladesh Medical College and Popular Medical College Specialized Hospitals from 2015 to 2018. Physical examination, anterior rhinoscopic and diagnostic nasal endoscopic examination was done in all patients after taking proper history in the ENT outpatient department. 168 patients were included with different types of septal deviation. Preoperative CT scanning both coronal, axial and sagittal view with $3 \mathrm{~mm}$ section was taken in all 168. Prior to CT all patients were asked to blow their nose. Endoscopic septoplasty was done in all 168 patients under general anesthesia. The patient who needed ancillary procedures with endoscopic septoplasty was recorded and presented in the result section. Their ages ranged between 10 to 70 years; 108 male and 60 female respectively.

\section{Study design}

- Study type:

A prospective study

- Study period:

From 2015 to 2018

- Study place:

Bangladesh Medical College Hospital

Popular Medical College Specialized Hospital

- Study Sample number: 168 patients

- Study population: Age ranged $10-70$ years

- Evaluation method:

$$
\begin{array}{ll} 
& \text { History } \\
& \text { Physical examination } \\
& \text { Anterior rhinoscopy } \\
& \text { Diagnostic nasal endoscopy } \\
& \text { Preoperative CT scanning } \\
\text { - Sampling type: } & \text { Random sampling }
\end{array}
$$

Statistical analysis: This was performed using the SPSS statistical software package. $P$ value of less than 0.05 was considered statistically significant.

\section{Inclusion criteria:}

- Obtained informed consent from all patients prior to inclusion in the study.

- Nasal septal deviation without sinonasal pathology.

- Nose blowing prior to CT.

- CT scans of nose and paranasal sinuses with 3-mm cut in coronal, axial and sagittal plane with bone window settings.

\section{Exclusion criteria:}

- Patients suffering from rhinosinusitis or nasal polyp, granulomatous diseases 
of the nose, allergic rhinitis or nasal masses, or with a past history of nasal surgery.

\section{Results}

168 patients included in this study. Preoperative CT was done in all patients after proper preparation. All the findings are shown in following tables. Among 168 patients, $35 \%$ reported in between 31 to 40 year of age followed by 21 to 31 year shown in Table 1.

Out of 168 patients, $69 \%$ belonged to male and female was $31 \%$ which is represented in Table 2.

CT scanning was done in all 168, amongst them HIT 32\%, CB/PMT 29\% and posterior deviation $14 \%$ and septal pneumatization $10 \%$ were recoded and shown in Table 3.

Nasal septal deviation was associated with maxillary cyst $40 \%$, maxillary sinusitis in $62(37 \%)$ patients, chronic otitis media $27 \%$, otitis media with effusion $20 \%$ and frontal sinusitis in $14 \%$ which is shown in Table 4.

Table 5 shows the surgical procedures done with endoscopic septoplasty. Only endoscopic septoplasty was carried out in 72 (43\%), septoplasty with FESS was done in 50\%, and other procedures are plotted in Table 5.

Table 1. Age distribution.

\begin{tabular}{ccc}
\hline Age in years & No of patients & $\%$ \\
\hline $10-20$ & 12 & 07 \\
$21-30$ & 48 & 29 \\
$31-40$ & 58 & 35 \\
$41-50$ & 26 & 15 \\
$51-60$ & 18 & 11 \\
$61-70$ & 06 & 04
\end{tabular}

Table 2. Sex distribution.

\begin{tabular}{ccc}
\hline Sex & No of patients & $\%$ \\
\hline Male & 116 & 69 \\
Female & 52 & 31 \\
\hline
\end{tabular}

Table 3. CT finding, anatomical variants with septal deviation (no 168).

\begin{tabular}{ccc}
\hline Anatomical variants & No of patients & $\%$ \\
\hline $\begin{array}{c}\text { Hypertrophied inferior turbinate(HIT) } \\
\text { Concha bullosa (CB)/Paradoxical middle turbinate } \\
\text { (PMT) }\end{array}$ & 54 & 32 \\
High deviation & 48 & 29 \\
Posterior deviation & 08 & 05 \\
Septal pneumatization & 24 & 14 \\
\hline
\end{tabular}


Table 4. CT finding-associated sinonasal and other pathologies.

\begin{tabular}{ccc}
\hline Pathologies & No of patients & $\%$ \\
\hline Maxillary sinusitis & 62 & 37 \\
Frontal sinusitis & 24 & 14 \\
Maxillary cyst & 68 & 40 \\
Otitis media with effusion & 34 & 20 \\
Chronic otitis media & 45 & 27 \\
\hline
\end{tabular}

Table 5. Endoscopic septoplasty with other procedures.

\begin{tabular}{ccc}
\hline Procedures & No of patients & $\%$ \\
\hline Endoscopic septoplasty only & 72 & 43 \\
Endoscopic septoplasty + Turbinoplasty & 54 & 32 \\
Endoscopic septoplasty +Conchplasty & 48 & 29 \\
Endoscopic septoplasty + FESS & 84 & 50 \\
Endoscopic septoplasty + Myringotomy & 34 & 20 \\
Endoscopic septoplasty + Tympanoplasty & 45 & 27 \\
\hline
\end{tabular}

\section{Discussion}

Nasal septal deviation is one of the commonest types of nasal obstruction encountered in otolaryngological practice all over the world and septoplasty is the common performed procedure. The use of endoscope in rhinology has significantly changed the concepts of septal surgery. Patients of nasal obstruction usually reported with the complaints of headache, postnasal rhinorrhea, facial pain, snoring, obstructive sleep apnea (OSA), otological and orbital symptoms, upper and lower respiratory tract manifestations for many years. Physical examination, anterior rhinoscopy and nasal endoscopy were considered 'the gold standard' for diagnosing septal deviation. Computed tomography (CT) can aid in evaluation of the deviated nasal septum from skull base to nasal floor, anatomical variants of the other nasal components and detect the associated sinonasal diseases [12] [13] [14]. The basic objective of endoscopic septoplasty is to relieve the symptom complexes caused by septal deviation and to treat associated pathological findings.

The advantages of preoperative CT prior to endoscopic septoplasty proved definite benefit on functional outcome that has been highlighted in this study. Although its role in the deviated nasal septum is debatable; and some studies have shown that it is unnecessary for the diagnosis and management of deviated septum [5]. Another group of study opined that it significantly influences the surgical management. These studies showed different results and opinions observed in the literature review subjecting computed tomography, septal deviation and septoplasty [5], although it has been aptly emphasized that CT is the "gold standard" in the diagnosis of sinonasal pathologies, opinion differs in the evaluation of septal deviation [5]. 
The costs and radiation hazards of CT bear an initial additional burden in septal surgery but the added advantages like correction of other anatomical variants and associated pathologies at the same sitting give rise to a long term definite benefit and thus avoid second surgery. With the introduction of Cone-Beam Computerized Tomography (CBCT) in the Head-neck region and dentistry, the costs and radiation hazards has been reduced to a great extent [6].

In this series, hypertrophied inferior turbinate was found in $39 \%$ and underwent turbinoplasty with septoplasty. The bony deformity along with the mucosal hypertrophy of the HIT in the contralateral side of septal deviation became evident on CT and that corresponds most of the published literature [14] [15]. So preoperative $\mathrm{CT}$ was useful as a deciding factor to detect the septal deviation and nasal turbinates' in three dimensional views on the surgical procedures of turbinate treatment with septoplasty.

Physical examination, anterior rhinoscopy and nasal endoscopy are the hall mark to evaluate most of the nasal pathologies. But it has definite limitation in the finding of $\mathrm{CB} / \mathrm{PMT}$ in its entire length and extension of the mucous hypertrophy and bony overgrowth. The advantage of CT is to evaluate clearly on coronal and axial CT [16]. The mucosal and bony structures of the middle turbinate and the angle of the septum were assessed using radiological analysis before septoplasty to have good result that was documented in this study.

OSA is being increasingly recognized as an important cause of morbidity and mortality around the globe and nasal obstruction accounts $50 \%$ of the total resistance of the upper air way resulting this disorder [17]. Nasal obstruction experienced by OSA patients are possibly due to deviated nasal septum, hypertrophied turbinate, chronic rhinosinusitis etc. but nasal septal deviation is one major cause. A high deviation is responsible for nasal obstruction and it is very difficult to recognize by conventional examination. 8 OSA patients were found with high deviation in our series, and that was evaluated in CT scanning. The high deviation of the septum also narrows the frontal recess resulting frontal sinusitis leading to headache [11]. Posterior deviation and septal penumatization are clearly revealed in computed tomography. Correction of the particular areas with preoperative proper planning in septal surgery alleviated symptoms completely and that was found in this series.

The posterior areas of the nasal cavities in the grossly deviated nasal septum or septal spur are practically unable to visualize by physical examination, AR and NE. CT scanning can provide details to the otolaryngologists/radiologists. Thus CT has the advantages to evaluate all those areas including the ostiomeatal complex and the associated paranasal sinus pathologies [18] [19]. In this series, maxillary sinusitis was found in 62 patients' with deviated nasal septum who needed septoplasty and functional endoscopic sinus surgery (FESS). CT revealed maxillary antral cyst in 68 patients; and very large cysts occupying $1 / 2$ to $2 / 3^{\text {rd }}$ of the maxillary sinus, underwent FESS. Small cysts did not require any surgical intervention. Out of 12 patients between 10 to 20 years of age, 3 patients were below 
15 years who had gross anterior septal deviation associated adenoidal hypertrophy. Their symptoms were relieved completely with septoplasty and adenoidectomy.

Many patients report to otolaryngologists with the complaints of ear block due to nasal obstruction and deviated nasal septum is the cause. The association of otitis media with nasal septal deviation has been found on CT scanning. It has been explained that deviation of the nasal septum interferes Eustachian tube function that changes the middle ear pressure and affects pneumatization of the mastoid [20] [21]. CT has the advantages to explore the mastoid, septum and nasopharynx [22] [23]. In our series otitis media with effusion and otitis media were documented in $27 \%$ and $20 \%$ of patients respectively. Endoscopic septoplasty and myringotomy in OME patients were carried out with a remarkable result. Chronic otitis media was also given special attention with septoplasty.

\section{Conclusion}

Preoperative CT of the nasal septum and its subsequent finding in the present study has a great advantage prior to surgery. Although it is expensive but patient enjoys a long term functional outcome. The advent of CBCT in the head neck and oral maxillofacial surgery draws special attention to minimize costs and radiation hazards than of computed tomography.

\section{Limitation of This Study}

Because of the financial constraints, radiation hazards and fear of doing CT scan in a box, collection of a large sample was not possible in this study. It is also intuitive that small samples might not be representative of the whole population so further large scale study should require to determine more results and outcome.

\section{Conflicts of Interest}

The authors have no funding, financial relationships, or conflicts of interest to disclose.

\section{References}

[1] Tomblinson, C.M., Cheng, M.-R., Lal, D. and Hoxworth, J.M. (2016) The Impact of Middle Turbinate Concha Bullosa on the Severity of Inferior Turbinate Hypertrophy in Patients with a Deviated Nasal Septum. American Journal of Neuroradiolo$g y$, 37, 1324-1330. https://doi.org/10.3174/ajnr.A4705

[2] Orhan, I., Aydin, S., Ormeci, T. and Yılmaz, F. (2014) A Radiological Analysis of Inferior Turbinate in Patients with Deviated Nasal Septum by Using Computed Tomography. American Journal of Rhinology \& Allergy, 28, 68-72. https://doi.org/10.2500/ajra.2014.28.4007

[3] Karatas, D., Yüksel, F., Sentürk, M., et al. (2013) The Contribution of Computed Tomography to Nasal Septoplasty. Journal of Craniofacial Surgery, 24, 1549-1551. https://doi.org/10.1097/SCS.0b013e3182902729

[4] Lechuga, L. and Weidlich, G.A. (2016) Cone Beam CT vs. Fan Beam CT: A Com- 
parison of Image Quality and Dose Delivered between Two Differing CT Imaging Modalities. Cureus, 8, e778. https://doi.org/10.7759/cureus.778

[5] Wotman, M. and Kacker, A. (2016) What Are the Indications for the Use of Computed Tomography before Septoplasty? The Laryngoscope, 126, 1268-1270. https://doi.org/10.1002/lary.25815

[6] Miracle, A.C. and Mukherji, S.K. (2009) Conebeam CT of the Head and Neck, Part 2: Clinical Applications. American Journal of Neuroradiology, 30, 1285-1292. https://doi.org/10.3174/ajnr.A1654

[7] Manjunath, R. and Chitradurga, S.V. (2013) Is Endoscopic Septoplasty Really Superior to Conventional Septoplasty? National Journal of Otolaryngology and Head Neck Surgery, 1, 16-18.

[8] Freer, O. (1992) The Correction of Deflections of the Nasal Septum with a Minimum of Traumation. Journal of the American Medical Association, 38, 636.

[9] Márquez, S., et al. (2014) Anatomy of the Nose and Paranasal Sinuses. In: Chang, C., Incaudo, G. and Gershwin, M., Eds., Diseases of the Sinuses, Springer, New York, 3-44.

[10] Park, D.H., Kim, T.M., Han, D.G. and Ahn, K.Y. (1998) Endoscopic-Assisted Correction of Deviated Nose. Aesthetic Plastic Surgery, 22, 190-195. https://doi.org/10.1007/s002669900190

[11] Server, E.A., Karagoz, Y., Çelebi, O.O., Yasak, A.G. and Yigit, O. (2019) Impact of High Septal Deviation in the Success of Frontal Sinus Surgery. B-ENT, 15, 319-324.

[12] El-Anwar, M.W., Ali, A.H., Almolla, R.M., Monaem, G.A., Raafat, A., Hassan, M.H. and Elsayed, M. (2020) Radiological Middle Turbinate Variations and Their Relation to Nasal Septum Deviation in Asymptomatic Adult. Egyptian Journal of Radiology and Nuclear Medicine, 51, Article No. 104. https://doi.org/10.1186/s43055-020-00222-1

[13] Poorey, V.K. and Gupta, N. (2014) Endoscopic and Computed Tomographic Evaluation of Influence of Nasal Septal Deviation on Lateral Wall of Nose and Its Relation to Sinus Diseases. Indian Journal of Otolaryngology and Head and Neck Surgery, 66, 330-335.

[14] Estomba, C.C., Schmitz, T.R., Echeverri, C.C., Reinoso, F.A.B., Velasquez, A.O. and Hidalgo, C.S. (2015) Compensatory hypertrophy of the Contralateral Inferior Turbinate in Patients with Unilateral Nasal Septal Deviation. A Computed Tomography Study. Otolaryngologia Polska, 69, 14-20.

[15] Lebowitz, R.A., Suzanne, K., Galli, D., Holliday, R.A. and Jacobs, J.B. (2001) Nasal Septal Deviation: A Comparison of Clinical and Radiological Evaluation. Operative Techniques in Otolaryngology, Head and Neck Surgery 12, 104-106.

https://doi.org/10.1053/otot.2001.24766

[16] Sedaghat, A.R., Kieff, D.A., Bergmark, R.W., Cunnane, M.E. and Busaba, N.Y. (2015) Radiographic Evaluation of Nasal Septal Deviation from Computed Tomography Correlates Poorly with Physical Exam Findings. International Forum of Allergy \& Rhinology, 5, 258-262. https://doi.org/10.1002/alr.21445

[17] Georgalas, C. (2011) The Role of the Nose in Snoring and Obstructive Sleep Apnea: An Update. European Archives of Oto-Rhino-Laryngology, 268, 1365-1373. https://doi.org/10.1007/s00405-010-1469-7

[18] Lee, D.C., Shin, J.H., Kim, S.W., et al. (2013) Anatomical Analysis of Nasal Obstruction; Nasal Cavity of Patients Complaining of Stuff Nose. The Laryngoscope, 123, 1381-1384. https://doi.org/10.1002/lary.23841 
[19] Günbey, E., Günbey, H.P., Uygun, S., Karabulut, H. and Cingi, C. (2015) Is Preoperative Paranasal Sinus Computed Tomography Necessary for Every Patient Undergoing Septoplasty? International Forum of Allergy \& Rhinology, 5, 839-845. https://doi.org/10.1002/alr.21545

[20] Sistani, S.S., Dashipour, A., Jafari, L. and Ghahderijani, B.H. (2019) The Possible Associations of Nasal Septal Deviation with Mastoid Pneumatization and Chronic Otitis. Open Access Macedonian Journal of Medical Sciences, 7, 2452-2456

[21] Kapusuz Gencer, Z., Ozkiriz, M., Okur, A., Karaoavus, S. and Saydam, S. (2013) The Possible Associations of Septal Deviation on Mastoid Pneumatization and Chronic Otitis. Otology \& Neurotology, 34, 1052-1052. https://doi.org/10.1097/MAO.0b013e3182908d7e

[22] Doyle, W. (2007) The Mastoid as a Functional Rate-Limiter of Middle Ear Pressure Change. International Journal of Pediatric Otorhinolaryngology, 71, 393-402. https://doi.org/10.1016/j.ijporl.2006.11.004

[23] Kumar, S.R.P. and Patel, S.V. (2020) A Prospective Study of Deviated Nasal Septum Giving Rise to Other ENT Pathologies. International Journal of Otorhinolaryngology and Head and Neck Surgery, 6, 303-310. https://doi.org/10.18203/issn.2454-5929.ijohns20200142 